\title{
Effect of low-dose exogenous surfactant on infants with acute respiratory distress syndrome after cardiac surgery: a retrospective analysis
}

\author{
Rongyuan Zhang ${ }^{1}$, Xu Wang ${ }^{1 *}$, Shoujun $\mathrm{Li}^{2}$ and Jun Yan ${ }^{2}$
}

\begin{abstract}
Background: Acute respiratory distress syndrome (ARDS) in infants undergoing cardiac surgery is associated with significant mortality and prolonged ventilation; surfactant administration may be a useful therapy. The purpose of this study is to evaluate the effect of low-dose exogenous surfactant therapy on infants suffering ARDS after cardiac surgery.

Methods: We conducted a case-control study of infants diagnosed with moderate-to-severe ARDS $\left(\mathrm{PaO}_{2} / \mathrm{FiO}_{2}<150\right)$ after cardiac surgery. A case was defined as a patient that received surfactant and standard therapy, while a control was defined as a patient that underwent standard therapy. The primary endpoint was the improvement in oxygenation index (OI) after 24-h of surfactant treatment; and secondary endpoints were the ventilator time and PICU time.

Results: Twenty-two infants treated with surfactant were matched with 22 controls. Early low-dose $(20 \mathrm{mg} / \mathrm{kg}) \mathrm{surfactant}$ treatment was associated with improved outcomes. After surfactant administration for 24 -h, the surfactant group was much better compared with the control group at the 24-h in OI (difference in average change from baseline, -6.7 [95\% $\mathrm{Cl},-9.3$ to -4.1$])(P<0.01)$ and ventilation index $(\mathrm{Vl}$, mean difference, $-11.9[95 \% \mathrm{Cl},-18.1$ to -5.7$])(P<0.01)$. Ventilation time and PICU time were significantly shorter in the surfactant group compared with the control group (133.6 $h \pm 27.2$ vs $218.4 h \pm 28.7, P<0.01 ; 10.7 d \pm 5.1$ vs $17.5 d \pm 6.8, P<0.01$ ). Infants in the surfactant group under 3 months benefit more from $\mathrm{Ol}$ and $\mathrm{VI}$ than the infants over 3 months in a preliminary exploratory analysis.

Conclusions: In infants with moderate-to-severe ARDS after cardiac surgery, early low-dose exogenous surfactant treatment could prominently improve oxygenation and reduce mechanical ventilation time and PICU time. Infants younger than 3 months may get more benefit of oxygenation than the older ones. Randomized controlled trials are needed to explore the effect of surfactant to ARDS of cardiac surgical infants.
\end{abstract}

Keywords: Infants, Pulmonary surfactant, ARDS, Cardiac surgery, Congenital heart disease

\footnotetext{
* Correspondence: fwpicu@163.com

${ }^{1}$ Department of Pediatric Intensive Care Unit, National Center for

Cardiovascular Disease and Fuwai Hospital, Chinese Academy of Medical Sciences, Peking Union Medical College, Beijing, People's Republic of China

Full list of author information is available at the end of the article
}

(c) The Author(s). 2020 Open Access This article is licensed under a Creative Commons Attribution 4.0 International License, which permits use, sharing, adaptation, distribution and reproduction in any medium or format, as long as you give appropriate credit to the original author(s) and the source, provide a link to the Creative Commons licence, and indicate if changes were made. The images or other third party material in this article are included in the article's Creative Commons licence, unless indicated otherwise in a credit line to the material. If material is not included in the article's Creative Commons licence and your intended use is not permitted by statutory regulation or exceeds the permitted use, you will need to obtain permission directly from the copyright holder. To view a copy of this licence, visit http://creativecommons.org/licenses/by/4.0/. The Creative Commons Public Domain Dedication waiver (http://creativecommons.org/publicdomain/zero/1.0/) applies to the data made available in this article, unless otherwise stated in a credit line to the data. 


\section{Background}

ARDS is recognized as a life-threatening respiratory complication in infants undergoing cardiac surgery and $\mathrm{CPB}$, associated with significant mortality and prolonged ventilation. Despite many efforts has been made to improve the survival rate, such as lung protective ventilation, fluid management, neuromuscular blockade, prone positioning, inhaled pulmonary vasodilators, and extracorporeal membrane oxygenation, mortality rate from ARDS remains 30-45\% [1]. Infants with CHD are more prone to CPB-ARDS, and severe lung injury may impair both lung mechanics and gas exchange [2].

Exogenous surfactant therapy is a routine therapeutic choice for pre-term newborns suffering respiratory distress syndrome. It is suggested that there may be expanded use of surfactant replacement for diseases such as meconium aspiration syndrome [3], pneumonia [4], bronchopulmonary dysplasia [5], and ARDS [6]. Surfactant replacement is an effective and safe therapy by rapidly improving oxygenation and mechanics, and it can improve lung physiology and clinical outcome [6]. Clinical trials reported that exogenous surfactant therapy could be beneficial for children and infants with ARDS without significant adverse effects [7].

The qualitative and quantitative changes in alveolar surfactant of patients with ARDS have been proven [7-9]. Similarly, due to endothelial cells damage, all post-cardiac surgery infants who had ARDS suffered surfactant dysfunction, destruction and inactivation [10-12]. Yet, limited study [13] showed preliminary therapeutic effect of surfactant therapy on these patients, especially, the association between age or drug dose and the efficacy of surfactant therapy. Therefore, this study will focus on: 1 evaluating whether low-dose surfactant therapy would improve oxygenation in infants who had ARDS after cardiac surgery with $\mathrm{CPB} ; 2$ trying to identify the most beneficial age of surfactant therapy.

\section{Methods}

\section{Study design and patients}

This is a retrospective, observational, case-control analysis, conducted from January 2015 to June 2019. Ethical Committee of Fuwai Cardiovascular Hospital approved the protocol (Approval NO. 2015-682), and written informed consent was obtained from all participants' parents.

The study was conducted in a PICU (40 beds) at a 1521-bedded tertiary medical care center in China. Patients entry criteria included: (1) less than 1 year old; (2) complete repair of CHD with $\mathrm{CPB}$; (3) $\mathrm{PaO}_{2} / \mathrm{FiO}_{2}$ lowered than 150 and had been mechanically ventilated for more than $48 \mathrm{~h}$. Exclusion criteria: (1) residual cardiac malformation that must be treated surgically; (2) ECMO; (3) cardiopulmonary resuscitation; (4) airway anomalies that will delay extubation; (5) ejection fracture $<45 \%$ (every patient received an ECHO when ARDS was diagnosed); (6) left atrial pressure $>12$ (Left atrial pressure of every infant was measured by placing a special catheter into the right atrium then punching through the interatrial septum).

There were 2 different strategies to deal with these infants in our center. Some patients preferred to adopt surfactant, who met the criteria. Other patients preferred to use standard treatment, for worrying about the potential complications such as airway obstruction, or for disliking extra economic burden. Everyone was offered surfactant at the beginning, but surfactant is not a part of our standard treatment protocol.

A total of 7569 children that had cardiac surgery were admitted to PICU, and 3414 of them were infants. 343 infants used mechanical ventilation above 2 days. 78 infants were diagnosed with moderate-to-severe ARDS $\left(\mathrm{PaO}_{2} / \mathrm{FiO}_{2}\right)$, and who matched inclusion and exclusion criteria. 22 infants who received surfactant in addition to standard care constituted surfactant group. In order to minimize potential bias caused by differences in baseline characteristics between groups, patients were matched in a 1:1 ratio using the following baseline features: age ( $\pm 30 \mathrm{~d})$, weight $( \pm 3 \mathrm{~kg})$, RACHS- 1 , and initial $\mathrm{PaO}_{2} / \mathrm{FiO}_{2}$ $( \pm 10)$. These 22 controls were also offered surfactant but declined (high cost 5, guardians' preference to use standard treatment 5, and guardians' refusal for worrying about the potential complications 12). It was a comparative study evaluating the changes in clinical status and outcome between the two groups. The primary endpoint was the improvement in OI after 24-h of surfactant treatment; and secondary endpoints were ventilator time and PICU time.

\section{Study drug}

Surfactant (Calf Pulmonary Surfactant for injection, produced by Shuang he Inc., Beijing, $\mathrm{CN}$ ) is a modified natural lung surfactant. It is produced by extracting the phospholipids, cholesterol, triglycerides, free fatty acids, surfactant protein $B$ and surfactant protein $C$ from bovine lung surfactant of newborn calf lungs. China Food and Drug Administration approved surfactant for neonatal respiratory distress syndrome.

The standard dose of surfactant is $50-100 \mathrm{mg} / \mathrm{kg}$ [14, 15], some patients may have side effects such as intense instant hemodynamic fluctuation and hypoxemia. Due to the high cost and the concern for airway obstruction, dose selection for the infant undergoing cardiac surgery was cautious. Considering that the native surfactant system of these infants was nearly normal before operation, and self-repairing systems of epithelial cells could replenish surfactant after CPB, a low dose of $20 \mathrm{mg} / \mathrm{kg}$ nature surfactant as the treatment dosage was used. 


\section{Study intervention}

All operations were performed by 2 senior surgeons. Patients in both groups had received standard care according to the hospital protocol. The basic care contained fluid resuscitation, enteral feeds and pain management, and other treatments including cardiac, diuretic, antiinflammatory. Vital signs, oximetry and hemodynamic parameters would be continuously monitored. The cardiac functions and circulatory blood volume status were obtained by pumping multiple vasoactive agents mainly including catecholamine drugs and giving adequate fluid supplement. Rescue protocol for any severe hemodynamic fluctuation would be prepared. Sedation and mechanical ventilation treatment would be strictly controlled. Supportive management and antibiotics were given as per unit policy. ARDS was diagnosed based on the standard recommended by the North AmericanEuropean Consensus Conference Committee [16]. The diagnosis of ARDS was confirmed by clinical, radiological and laboratory findings.

Lung protective ventilation strategy was applied to all infants before enrollment. All infants were intubated and supported by mechanical ventilation with synchronized intermittent mandatory ventilation mode of the ventilator $\left(\mathrm{PB} 840^{\circ}\right)$. Ventilator settings were adjusted to arterial blood gas results. The peak inspiratory pressure was adjusted to reach a tidal volume goal of $6 \mathrm{ml} / \mathrm{kg}$ to $8 \mathrm{ml} /$ $\mathrm{kg}$. To keep the $\mathrm{PaCO}_{2}$ below $45 \mathrm{mmHg}$, the inspiratory time would be set at approximately $0.5 \mathrm{~s}$, with respiratory rate $25-40 / \mathrm{min}, \mathrm{PEEP} 4-8 \mathrm{cmH}_{2} \mathrm{O}$. Also, to maintain arterial oxygen saturation above $85 \%$ and $\mathrm{PaO}_{2}$ above $50 \mathrm{mmHg}$, peak inspiratory pressure and $\mathrm{FiO}_{2}$ needed to be adjusted.

Natural surfactant (bovine) would be given $20 \mathrm{mg} /$ $\mathrm{Kg}(35 \mathrm{mg} / \mathrm{ml})$. After receiving the written parental permission, surfactant would be instilled into the trachea via an endotracheal tube using a small catheter in 4 equal aliquots, which would be instilled in four different positions (left, head up then down, right). Manual ventilation with $100 \% \mathrm{O}_{2}$ would be applied for 5 min after the treatment. With concomitant sedation and muscle relaxation, the next tracheal suctioning would be performed at least $4 \mathrm{~h}$ later. The acute effects of surfactant therapy would be evaluated 24- $\mathrm{h}$ after the treatment. Vital signs were monitored continuously and recorded for 60 min after the intervention. Chest radiographs were acquired before and after surfactant administration every day.

\section{Data collection}

Data was entered on a pre-designed case record form from the patients' archived files. The data extracted included patient demographics, blood gases, ventilator settings, complication, total time on ventilator, total time in PICU and clinical outcomes. Ventilator days were counted from the first day that a patient received mechanical ventilation. Ventilator parameters were recorded before the start of surfactant administration. After surfactant treatment, OI and VI were derived from the measured data. OI was calculated via mean airway pressure ${ }^{*} \mathrm{FiO}_{2}{ }^{*} 100 / \mathrm{PaO}_{2}$ and VI was calculated via $\mathrm{PaCO}_{2}$ * peak inspiratory pressure * respiratory rate/1000.

The baseline demographic and clinical characteristics that were collected were age, weight, sex, RACHS-1, total on-pump time, aortic clamping time, $\mathrm{OI}, \mathrm{VI}, \mathrm{PaO}_{2} /$ $\mathrm{FiO}_{2}, \mathrm{PaO}_{2}$ and the status of the patient within the time of inclusion (Table 1). In addition, the severity of illness at the time of inclusion was recorded and assessed by using the SOFA score [17]. Moreover, the daily vital signs, urine output, laboratory data, ventilator settings, vasopressor dosage were extracted.

\section{Statistical analysis}

Qualitative data were presented as frequencies and percentages, whereas quantitative data were presented as mean, standard deviation. The unpaired t-test was used for comparison between patients in surfactant group and control group. Classification data number (percentage) aggregation, and Chi-square or Fisher's exact test. The cumulative percentages of extubated patients were analyzed using Kaplan-Meier survival analysis with the logrank test. The data was analyzed using SPSS version 20.0. The $p$-value of $<0.05$ was considered as statistically significant.

\section{Results}

\section{Patient characteristics}

Detailed demographic information of infants in surfactant group and control group are listed in Table 1. There was no significant difference in age, weight, sex, $\mathrm{RACH}$ $\mathrm{S}-1$, total on-pump time and aortic clamping time between the surfactant group and the control group. There was no significant difference in OI, VI, $\mathrm{PaO}_{2} / \mathrm{FiO}_{2}$ and $\mathrm{PaCO}_{2}$ between the two groups at the beginning (Table 1 ). The mean time of surfactant administration was 3 days after operation.

\section{Clinical usefulness of low-dose exogenous surfactant}

The treatment was well tolerated as well. No side effects and complications were observed during surfactant treatment. Compared with the control group, infants of the surfactant group showed better improvement in OI, VI and $\mathrm{PaO}_{2} / \mathrm{FiO}_{2}$ ratio. All variables before and after surfactant therapy is given in Table 2 and Figs. 1, 2 and 3. Infants receiving surfactant had significantly shorter ventilation time and 
Table 1 Study population and baseline characteristics

\begin{tabular}{|c|c|c|c|}
\hline Characteristic & $\begin{array}{l}\text { Surfactant } \\
n=22\end{array}$ & $\begin{array}{l}\text { Control } \\
n=22\end{array}$ & $P$ Value \\
\hline Age (months) & $5.5( \pm 1.6)$ & $5.3( \pm 1.8)$ & 0.698 \\
\hline Weight (kg) & $6.2( \pm 1.2)$ & $6.3( \pm 1.5)$ & 0.808 \\
\hline Sex (male/female) & $13 / 9$ & $12 / 10$ & 0.585 \\
\hline RACHS-1 ॥ (\%) & 7(31.8) & $7(31.8)$ & \\
\hline RACHS-1 III (\%) & $8(36.3)$ & $8(36.3)$ & \\
\hline RACHS-1 IV (\%) & $7(31.8)$ & 7(31.8) & \\
\hline Total on-pump time (min) & $146.8( \pm 44.5)$ & $138.4( \pm 35.8)$ & 0.382 \\
\hline Aortic clamping time (min) & $57.3( \pm 18.1)$ & $52.3( \pm 15.2)$ & 0.326 \\
\hline Time of inclusion (days after operation) & $3.0( \pm 1.6)$ & $2.9( \pm 1.4)$ & 0.826 \\
\hline Ol & $13.9( \pm 3.8)$ & $13.2( \pm 3.2)$ & 0.512 \\
\hline $\mathrm{Vl}$ & $42.4( \pm 7.6)$ & $40.6( \pm 8.4)$ & 0.460 \\
\hline $\mathrm{PaO}_{2} / \mathrm{FiO}_{2}$ & $88.5( \pm 15.4)$ & $90.3( \pm 17.5)$ & 0.719 \\
\hline $\mathrm{PaCO}_{2}$ & $43.0( \pm 5.8)$ & $45.8( \pm 7.5)$ & 0.173 \\
\hline SOFA score & $10.5( \pm 2.9)$ & $11.2( \pm 3.1)$ & 0.325 \\
\hline Use of neuromuscular blockers (\%) & $12(54.5)$ & 14(63.6) & 0.106 \\
\hline Vasopressor use (\%) & $22(100)$ & $22(100)$ & \\
\hline Body temperature $\left({ }^{\circ} \mathrm{C}\right)$ & $36.5( \pm 0.4)$ & $36.4( \pm 0.5)$ & 0.468 \\
\hline Mean arterial pressure $(\mathrm{mmHg})$ & $44.6( \pm 18.4)$ & $47.2( \pm 15.6)$ & 0.616 \\
\hline White cell count $\left(10^{9} / \mathrm{L}\right)$ & $13.4( \pm 4.2)$ & $12.1( \pm 3.8)$ & 0.288 \\
\hline $\mathrm{CRP}(\mathrm{mg} / \mathrm{L})$ & $58.6( \pm 20.7)$ & $49.2( \pm 16.1)$ & 0.100 \\
\hline Latate $(\mathrm{mmol} / \mathrm{L})$ & $1.1( \pm 0.4)$ & $0.8( \pm 0.3)$ & 0.013 \\
\hline Creatinine (umol/L) & $64.8( \pm 32.2)$ & $72.1( \pm 20.5)$ & 0.375 \\
\hline Clinical pneumonia+ CPB injury (\%) & $10(45.5)$ & $12(54.5)$ & 0.818 \\
\hline Proved pneumonia (\%) & $7(31.8)$ & $9(40.9)$ & 0.358 \\
\hline Viral, non-RSV (\%) & 2(9) & $3(13.6)$ & 0.000 \\
\hline RSV (\%) & $1(4.5)$ & 2(9) & 0.000 \\
\hline Bacterial (\%) & $3(13.6)$ & $4(18)$ & 0.003 \\
\hline CPB injury (\%) & $12(54.5)$ & $10(45.5)$ & 0.818 \\
\hline
\end{tabular}

Surfactant: patients who had ARDS after cardiac surgery received standard treatment plus exogenous surfactant. Control: patients who had ARDS after cardiac surgery received standard treatment only. The data are presented as mean \pm standard; qualitative data are presented as numbers (\%)

RACHS-1 risk adjustment congenital heart surgery-1, CPB cardiopulmonary bypass, $V I$ ventilation index, OI oxygenation index

PICU time (Table 2). All patients were extubated within 15 days. Infants in surfactant group were extubated earlier than control group $(P<0.01)$ (Fig. 4).

The surfactant group was better compared with the control group at the 6-h with respect to both OI (difference in average change from baseline, - 6.4 [95\% CI, 9.0 to -3.8$])(P<0.01)$ and VI (mean difference, -14.8 [95\% CI, -21.5 to -8.1$])(P<0.01)$. At the 24 -h followup, the change from baseline in OI (difference, -6.7 [95\% CI, -9.3 to -4.1$])(P<0.01)$ and VI (mean difference,-11.9 [95\% CI, -18.1 to -5.7$])(P<0.01)$ were much better in the surfactant group than the control group $(P<0.01)$. (Figs. 1 and 2.
Similarly, compared with the control group, surfactant treatment was associated with greater improvement $(P<0.01)$ at 6 -h in $\mathrm{PaO}_{2} / \mathrm{FiO}_{2}$ (mean difference, 41.6 [95\% CI, 20.1 to 63.1]) $(P<0.01)$. At the $24-\mathrm{h}$ follow-up, the change from baseline in $\mathrm{PaO}_{2} / \mathrm{FiO}_{2}$ (mean difference, 90.6 [95\% CI, 68.2 to 113.0]) $(P<$ 0.01) was much higher in the surfactant group than the control group (Fig. 3).

None of the patients showed significant clinical deterioration and changes in hemodynamic status and other vital signs with the application of surfactant (Table 2). Five patients (22.7\%) in control group and 2 patients (9.1\%) in surfactant group had 
Table 2 Clinical outcomes (in 30 days)

\begin{tabular}{llll}
\hline Characteristic & $\begin{array}{l}\text { Surfactant } \\
n=22\end{array}$ & $\begin{array}{l}\text { Control } \\
n=22\end{array}$ & $P$ Value \\
\hline $\begin{array}{l}\text { Alive/death (n/n) } \\
\text { Complication }\end{array}$ & $22 / 0$ & $22 / 0$ & - \\
$\quad$ Pneumothorax (\%) & $2(9)$ & $5(22.7)$ & 0.001 \\
$\quad$ Digestive tract hemorrhage (\%) & $0(0)$ & $1(4.5)$ & 0.000 \\
Rescue treatment (\%) & & & \\
$\quad$ CPAP (\%) & $3(13.6)$ & $8(36.3)$ & 0.015 \\
$\quad$ Re tracheal intubation (\%) & $1(4.5)$ & $2(9)$ & 0.000 \\
$\quad$ PD (\%) & $1(4.5)$ & $2(9)$ & 0.000 \\
$\quad$ HFOV (\%) & $0(0)$ & $1(4.5)$ & 0.000 \\
Total time on ventilator (h) & $133.6 \pm 27.2$ & $218.4 \pm 28.7$ & 0.000 \\
Total time in PICU (day) & $10.7 \pm 5.1$ & $17.5 \pm 6.8$ & 0.001 \\
\hline
\end{tabular}

Surfactant: patients who had ARDS after cardiac surgery received standard treatment plus exogenous surfactant. Control: patients who had ARDS after cardiac surgery received standard treatment only. The data are presented as mean \pm standard; qualitative data are presented as numbers (\%)

$C P A P$ treatment with continuous positive airway pressure, $P D$ treatment with peritoneal dialysis, HFOV treatment with high frequency oscillatory ventilator pneumothorax; and $1(4.5 \%)$ patient in control group had digestive hemorrhage, none happened in surfactant group $(P<0.01)$. Three patients $(13.6 \%)$ in surfactant group and $8(36.3 \%)$ in control group needed CPAP after extubation $(P<0.01)$. There were $2(9 \%)$ and $1(4.5 \%)$ patients in control group and surfactant group needing retracheal intubation and peritoneal dialysis respectively. One (4.5\%) patient in control group needed HFOV, none happened in surfactant group $(P<0.01)$.

\section{Exploratory subgroup analysis}

The 22 patients in surfactant group were assigned to younger than 3 months subgroup (10 infants) and older than 3 months subgroup (12 infants). RACHS-1, total on-pump time and aortic clamping time of the two subgroups were similar $(P<0.01)$ (Table 3$)$. For the subgroups based on age have very low numbers, preliminary exploratory analysis showed: surfactant showed better efficacy in OI and VI in the less than 3 months subgroup (Table 4). There was no statistical

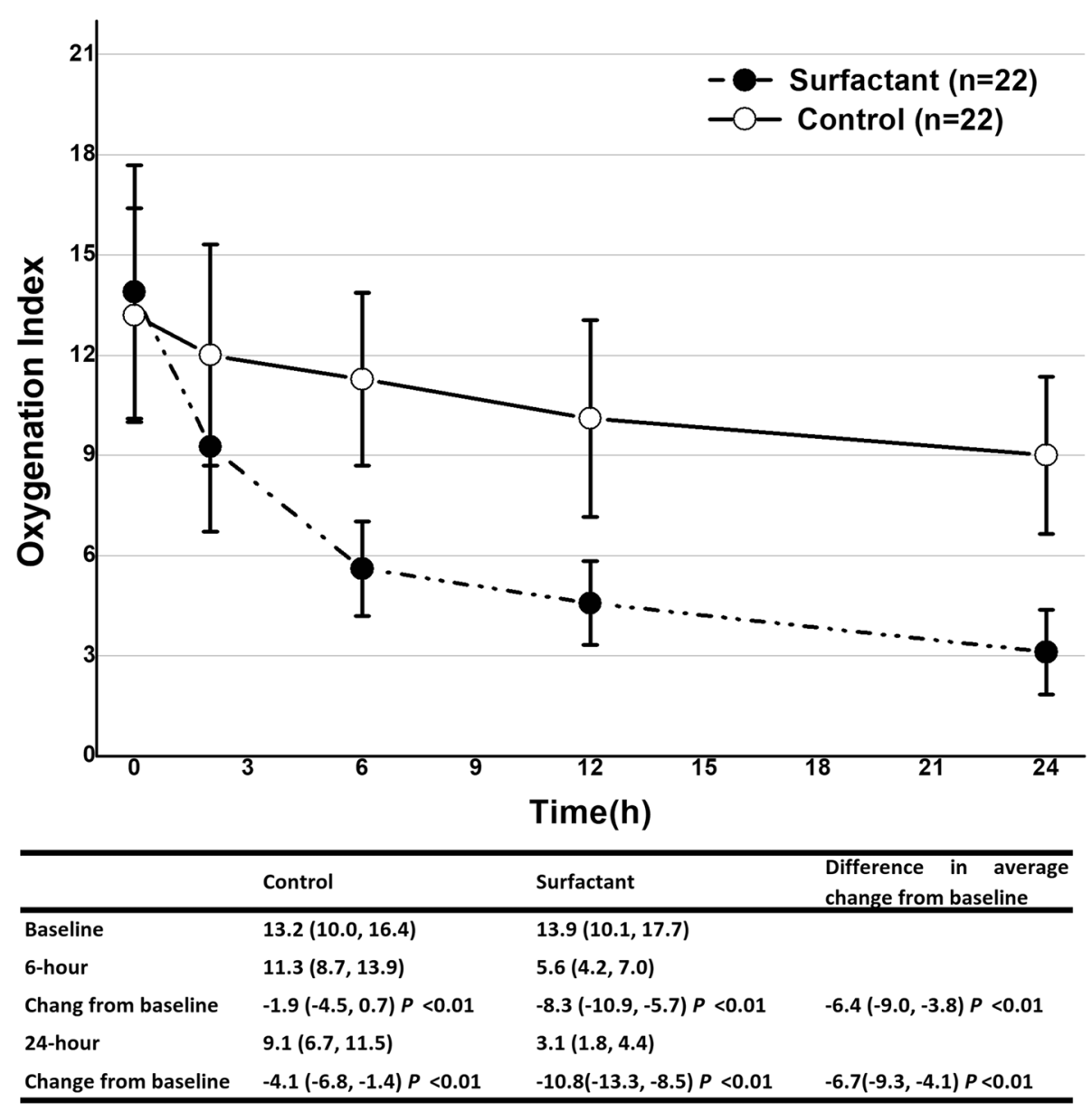

Fig. 1 Change of Oxygenation Index (OI) before and after surfactant treatment compared with the control 


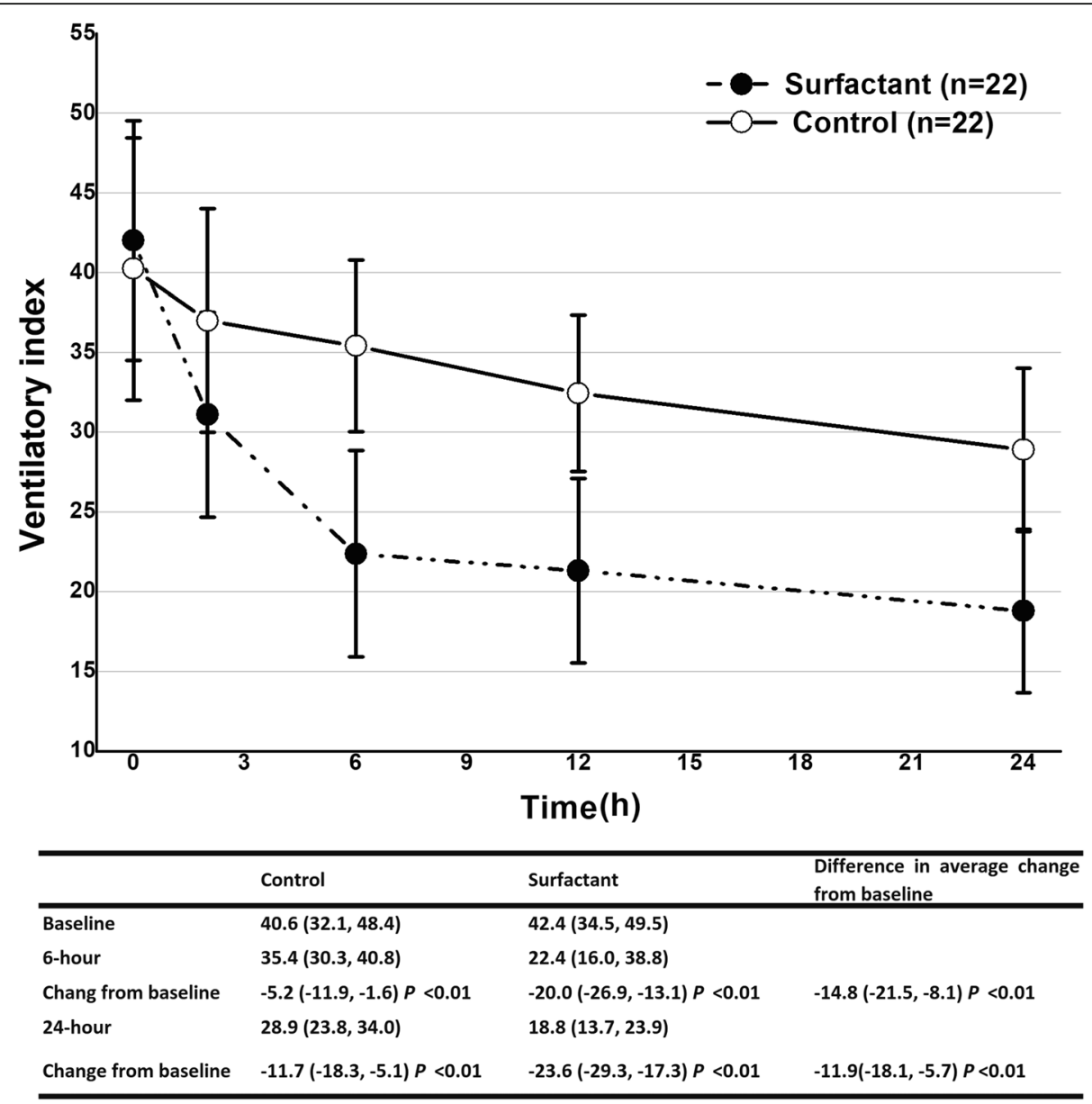

Fig. 2 Change of Ventilatory Index (VI) before and after surfactant treatment compared with the control

difference in ventilator time and PICU time between the two subgroups (Table 3).

\section{Discussion}

In this study, with the treatment of low dose surfactant, rapid improvement in oxygenation, and significant decrease in duration of ventilator time and PICU time were observed. This is the first study about lowdose surfactant therapy in infants after cardiac surgery with CPB. Preliminary exploratory analysis showed infants younger than 3 months benefited more from oxygenation improvement than the infants older than 3 months.

The pathophysiology of ARDS following CPB has not been completely defined yet. Inflammatory response induced by CPB could be exacerbated by accumulation of cytokines, and infants seem to be less susceptible to this response [18]. Meanwhile, prolonged mechanical ventilation can worsen ARDS by damaging the alveolocapillary barrier in the lungs [19]. The reduced compliance and a ventilation- perfusion mismatch hinted that the surfactant system was damaged [20, 21]. Nearly one third of postcardiac surgery infants have been found surfactant components changes [22]. Exogenous surfactant may contribute in preventing the surfactant system from developing extreme disturbance.

Respiratory tract infections are the most common risk factors of ARDS in infants, and $\mathrm{CPB}$ is a risk factor reported in cardiac patients. Around $50 \%$ of patients in each group had clinical courses complicated by pneumonia, infants with unrepaired CHD often suffer from malnutrition and have weakened immune systems. They are more susceptible to lower respiratory tract infections before surgery, while postoperatively they are at risk for ARDS. The other $50 \%$ of infants' ARDS were cause for CPB. Children with cardiac disease may be particularly susceptible to deleterious $\mathrm{CPB}$ interactions induced by positive pressure ventilation. Surfactant dysfunction and inactivation are key contributors to the pathophysiology of ARDS by inducing areas of atelectasis and intrapulmonary 


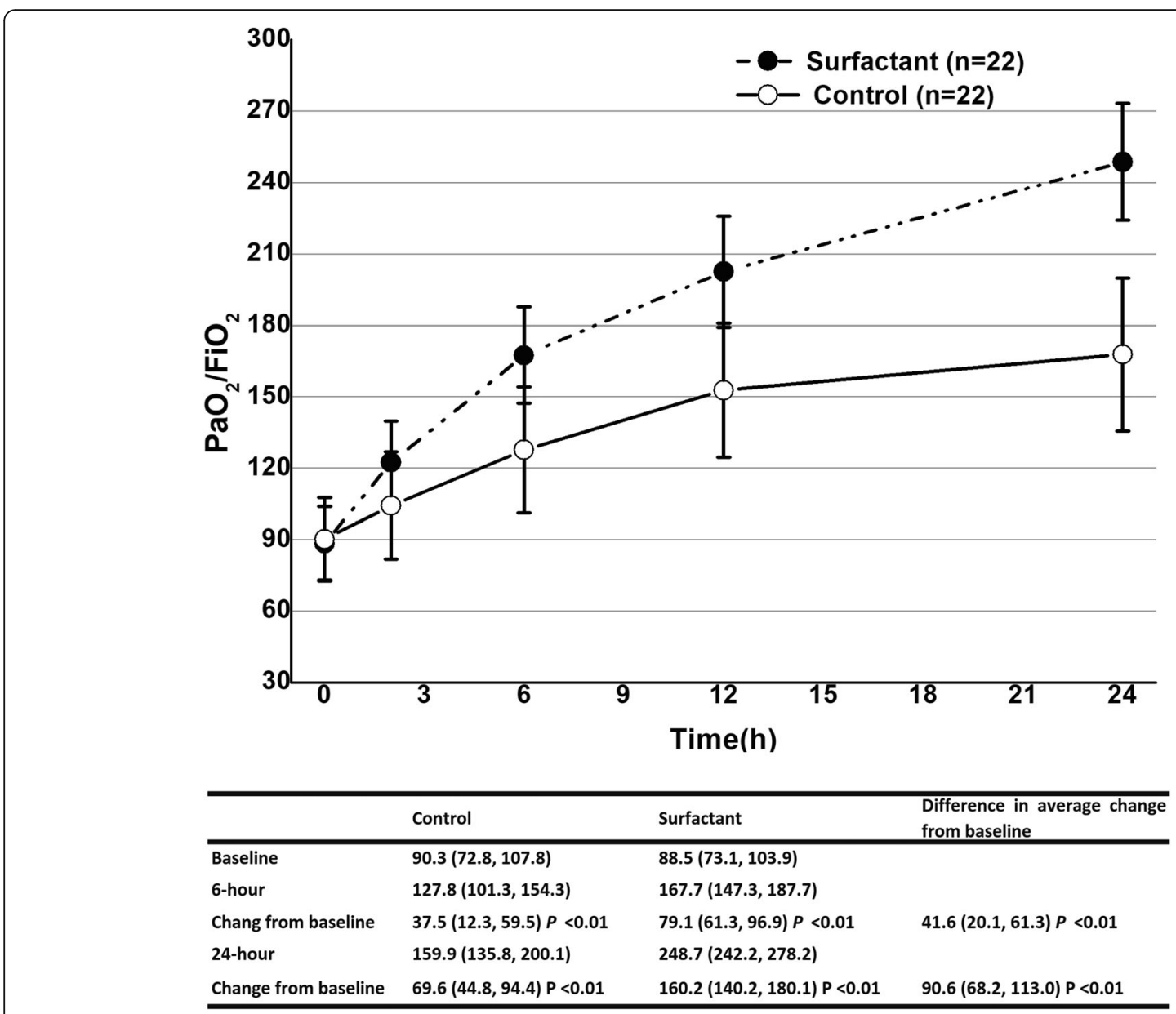

Fig. 3 Changes of $\mathrm{PaO}_{2} / \mathrm{FiO}_{2}$ before and after surfactant treatment compared with the control. $\mathrm{FiO}_{2}=$ fraction of inspired oxygen, $\mathrm{PaO} \mathrm{O}_{2}=$ arterial partial pressure of oxygen

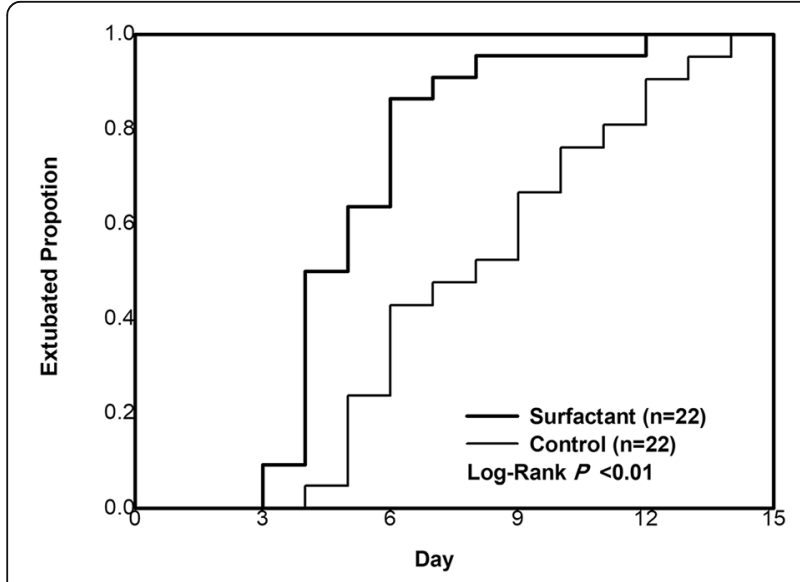

Fig. 4 Extubated proportion of surfactant compared with control shunting, which reduce lung volumes and compliance. Because failure to improve clinically over the first several days, particularly regarding oxygenation, predicts a complicated course and greater mortality risk, oxygenation improvement is particularly important for these infants [23].

The study population was strictly defined according to inclusion and exclusion criteria. Most infants with mild lung injury could be well managed with common treatment such as mechanical ventilation. As a clinical predictive tool, a $\mathrm{PaO}_{2} / \mathrm{FiO}_{2}$ threshold of 150 was used in this study. Surfactant would be given as rescue treatment once mechanical ventilation failed in improving the oxygenation. Oxygenation improvement was reported in previous study $[13,24,25]$. Unlike previous studies, a decrease in the duration of ventilation and total time of PICU could also be observed.

Preliminary exploratory analysis showed: infants younger than 3 months achieved faster recovery of 
Table 3 Baseline characteristics and clinical outcomes of subgroups of surfactant group

\begin{tabular}{llll}
\hline Characteristic & $\begin{array}{l}\leq 3 \text { months subgroup } \\
n=10\end{array}$ & $\begin{array}{l}>3 \text { months subgroup } \\
n=12\end{array}$ & $P$ Value \\
\hline Age (months) & $3.7 \pm 0.8$ & $7.0 \pm 2.1$ & 0.000 \\
Weight (kg) & $5.3 \pm 1.2$ & $7.3 \pm 2.2$ & 0.018 \\
Sex (male/female) & $6 / 4$ & $7 / 5$ & $4(33)$ \\
RACHS-1 II (\%) & $3(30)$ & $4(33)$ & 0.671 \\
RACHS-1 III (\%) & $4(40)$ & $4(33)$ & 0.228 \\
RACHS-1 IV (\%) & $3(30)$ & $146.9 \pm 46.7$ & 0.387 \\
Total on-pump time (min) & $155.2 \pm 43.6$ & $49.6 \pm 20.6$ & 0.228 \\
Aortic clamping time (min) & $52.0 \pm 19.4$ & $123.6 \pm 47.5$ & 0.673 \\
Ventilation time (h) & $140.2 \pm 32.8$ & $10.7 \pm 4.0$ & 0.782 \\
PICU time (day) & $12.8 \pm 4.2$ & & 0.361 \\
\hline
\end{tabular}

The data are presented as mean \pm standard; qualitative data are presented as numbers (\%)

pulmonary function. Age is a risk factor of lung damage during $\mathrm{CPB}$ [26]. Lung ischemia-reperfusion was more severe in the infants younger than 3 months, probably because of the combination of low antioxidant capacity and overproduction of reactive oxygen species. And the rescue surfactant treatment would help with the avoidance of further lung injury and the maintenance of intact alveolar barrier.

Surfactant treatment aims to instill a liquid-surfactant mixture directly into the lung airway tree. By a mathematical model of 3D lung structure [27], the surfactant liquid plug deposits a coating film on the airway wall and then splits unevenly at the bifurcation due to gravity. Calculation results show the neonatal lung is a well-mixed compartment, whereas the older is not. That may partly explain why infants younger than 3 months get more benefit of oxygenation than the older ones, and the spread efficiency and homogeneity of surfactant may be different in the two subgroups. Comparisons between infants over and under than 3 months may help to promote future clinical practice. Positive surfactant treatment may give young infants more benefit in earlier stage.
Single-centered data and institution-specific variables may influence the results. More data are necessary to better understand the risks and benefits of low-dose surfactant therapy in infants with moderate-to-severe ARDS after cardiac surgery, and a multi-center randomized controlled trial for this topic is also necessary.

\section{Conclusions}

ARDS continues to be associated with prolonged mechanical ventilation in CHD infants undergoing cardiac surgery and CPB. There is an urgent need for therapies which could alter the outcome of the disease. This study has presented that low-dose surfactant therapy could be safely and effectively applied in the treatment of infants with ARDS, surfactant instillation has effects of improving oxygenation (OI, VI and $\mathrm{PaO}_{2} / \mathrm{FiO}_{2}$ ratio) and reducing the mechanical ventilation time and ICU time. There is justification to test the role of exogenous surfactant in cardiac surgical babies who develop ARDS in randomized controlled trials.

Table 4 Oxygenation index and ventilation index of subgroup in surfactant group (in 30 days)

\begin{tabular}{llll}
\hline Characteristic & $\begin{array}{l}\leq 3 \text { months subgroup } \\
n=10\end{array}$ & $\begin{array}{l}>3 \text { months subgroup } \\
n=12\end{array}$ & Difference in average change from baseline \\
\hline Baseline of OI & $16.3(13.2,19.4)$ & $11.9(7.9,15.9)$ & - \\
24-h & $3.7(3.0,4.4)$ & $2.9(1.6,4.2)$ & $3.6(1,6.2) P<0.01$ \\
Change from baseline & $12.6(8.8,16.4)$ & $9.0(7.6,10.4)$ & - \\
Baseline of VI & $49.2(41.3,57.1)$ & $39.6(33.3,45.9)$ & - \\
24-h & $21.2(17.0,25.4)$ & $19.4(16.2,22.6)$ & $17.9(12.2,23.4) P<0.01$ \\
Change from baseline & $28.0(21.9,34.1)$ & $10.1(5.3,15.9)$ &
\end{tabular}

Values are presented as mean $(95 \% \mathrm{Cl})$

Ol oxygenation index, VI ventilation index 


\section{Abbreviations}

ARDS: Acute respiratory distress syndrome; CHD: Congenital heart disease; CPB: Cardiopulmonary bypass; PICU: Pediatric cardiac surgical intensive care unit; $\mathrm{PaO}_{2} / \mathrm{FiO}_{2}$ : Arterial oxygen concentration to the fraction of inspired oxygen; ECMO: Extracorporeal membrane oxygenation; RACHS-1: Risk adjustment congenital heart surgery-1; OI: Oxygenation index; VI: Ventilation index; CPAP: Continuous positive airway pressure; HFOV: High frequency oscillatory ventilation; Cl: Confidence interval

\section{Acknowledgements}

Not applicable.

\section{Authors' contributions}

All authors participated in the interpretation of the study results and review of the manuscript. RY $Z$ designed and conducted all experiments and drafted the manuscript. XW planned the study and drafted the manuscript. SJ $L$ and JY contributed to the study design and the revision of the manuscript. All authors read and approved the final manuscript.

\section{Funding}

The work was supported by the Central Public Welfare Scientific Research Fund of China [2016-F01] and the National Key R\&D Program of China [2017YFC1308100]. The funding bodies had no role in the design of the study and collection, analysis, and interpretation of data and in writing the manuscript.

\section{Availability of data and materials}

The datasets used and analysed during the current study are available from the corresponding author on reasonable request.

\section{Ethics approval and consent to participate}

Ethical Committee of Fuwai Cardiovascular Hospital approved the protocol (Approval NO. 2015-682), and written informed consent was obtained from all participants' parents.

\section{Consent for publication}

Not applicable.

\section{Competing interests}

The authors declare no competing interests.

\section{Author details}

'Department of Pediatric Intensive Care Unit, National Center for Cardiovascular Disease and Fuwai Hospital, Chinese Academy of Medical Sciences, Peking Union Medical College, Beijing, People's Republic of China. ${ }^{2}$ Department of Surgery, Pediatric Cardiac Center, National Center for Cardiovascular Disease and Fuwai Hospital, Chinese Academy of Medical Sciences, Peking Union Medical College, Beijing, People's Republic of China.

Received: 2 January 2020 Accepted: 29 July 2020

Published online: 06 August 2020

\section{References}

1. Máca J, Jor O, Holub M, Sklienka P, Burša F, Burda M, et al. Past and present ARDS mortality rates: a systematic review. Respir Care 2017; 62:113-122. http://doi: https://doi.org/10.4187/respcare.04716.

2. Li SL, Wang X, Li SJ, Yan J. High-frequency oscillatory ventilation for cardiac surgery children with severe acute respiratory distress syndrome. Pediatr Cardiol 2013;34:1382-1388. http://doi: https://doi.org/10.1007/s00246-0130655-y.

3. Bandiya P, Nangia S, Saili A. Surfactant lung lavage vs. standard Care in the Treatment of meconium aspiration syndrome-a randomized trial. J Trop Pediatr 2019;65:114-121. http://doi: https://doi.org/10.1093/tropej/fmy024.

4. Deshpande S, Suryawanshi P, Ahya K, Maheshwari R, Gupta S. Surfactant therapy for early onset pneumonia in late preterm and term neonates needing mechanical ventilation. J Clin Diagn Res 2017;11:9-12. http://doi: https://doi.org/10.7860/JCDR/2017/28523.10520.

5. Keszler M, Sant'Anna G. Mechanical ventilation and Bronchopulmonary dysplasia. Clin Perinatol 2015;42:781-796. http://doi: https://doi.org/10.1016/ j.clp.2015.08.006.
6. Bautin A, Khubulava G, Kozlov I. Surfactant therapy for patients with ARDS after cardiac surgery. J Liposome Res 2006;16:265-272. http://doi: https:// doi.org/10.1080/08982100600850997.

7. Amigoni A, Pettenazzo A, Stritoni V, Circelli M. Surfactants in acute respiratory distress syndrome in infants and children: past, present and future. Clin Drug Investig 2017;37:729-736. http://doi: https://doi.org/10. 1007/s40261-017-0532-1.

8. Willson DF, Chess PR, Notter RH. Surfactant for pediatric acute lung injury. Pediatr Clin N Am 2008:55:545-575. http://doi: https://doi.org/10.1016/j.pcl. 2008.02.016.

9. Playfor SD, Nootigattu VK. Exogenous surfactant in paediatric acute lung injury and acute respiratory distress syndrome. Curr Drug Saf 2006;1:159168. http://doi: https://doi.org/10.2174/1574886606776930553.

10. Haslam PL, Baker CS, Hughes DA, MacNaughton PD, Moat NE, Dewar A, et al. Pulmonary surfactant composition early in development of acute lung injury after cardiopulmonary bypass: prophylactic use of surfactant therapy. Int J Exp Pathol 1997;78:277-289. http://doi: https://doi.org/10.1046/j.13652613.1997.330364.x.

11. Ozguler IM, Burma O, Uysal A, Akbulut H. Rosuvastatin lowers systemic inflammatory response in coronary artery bypass graft accompanied by cardiopulmonary bypass surgery: a randomized controlled study. Clin Invest Med. 2015;38:154-163. http://doi: https://doi.org/10.25011/cim.v38i4.24260.

12. Wagner R, Piler P, Uchytil B, Halouzka R, Kovaru H, Bobkova M, et al. Systemic inflammatory response syndrome is reduced by preoperative plasma-thrombo-leukocyte aphaeresis in a pig model of cardiopulmonary bypass. Biomed Pap Med Fac Univ Palacky Olomouc Czech Repub 2016;160: 399-406. http://doi: https://doi.org/10.5507/bp.2016.010.

13. Cai J, Su Z, Zhou Y, Shi Z, Shi Z, Xu Z, Liu J, et al. Beneficial effect of exogenous surfactant in infants suffering acute respiratory distress syndrome after cardiac surgery. Eur J Cardiothorac Surg 2011;40:557-562. http://doi: https://doi.org/10.1016/j.ejcts.2011.01.008.

14. Halliday HL, Tarnow-Mordi WO, Corcoran JD, Patterson CC. Multicentre randomised trial comparing high and low dose surfactant regimens for the treatment of respiratory distress syndrome (the Curosurf 4 trial). Arch Dis Child 1993;69:276-280. http://doi: https://doi.org/10.1136/adc.69.3_spec_no.276.

15. Möller JC, Schaible T, Roll C, Schiffmann JH, Bindl L, Schrod L, et al. Treatment with bovine surfactant in severe acute respiratory distress syndrome in children: a randomized multicenter study. Intensive Care Med 2003;29:437-446. http://doi: https://doi.org/10.1007/s00134-003-1650-1.

16. Bernard GR, Artigas A, Brigham KL, Carlet J, Falke K, Hudson L, et al. The American-European consensus conference on ARDS: definitions, mechanisms, relevant outcomes, and clinical trial coordination. Am J Respir Crit Care Med 1994; 149:818-824. http://doi: https://doi.org/10.1164/ajrccm. 149.3.7509706

17. Vincent JL, Moreno R, Takala J, Willatts S, De Mendonca A, Bruining H, et al. The SOFA (sepsis-related organ failure assessment) score to describe organ dysfunction/failure. On behalf of the working group on sepsis-related problems of the European Society of Intensive Care Medicine. Intensive Care Med 1996;22:707-710. http://doi: https://doi.org/10.1007/BF01709751.

18. Fujii Y, Shirai M, Pearson JT, Dziuba F, Horke A, Kaussen T, et al. Changes in inflammatory response during and after cardiopulmonary bypass using a rat extracorporeal circulation model. Conf Proc IEEE Eng Med Biol Soc 2015; 2015:957-960. http://doi: https://doi.org/10.1109/EMBC.

19. Hamlington KL, Bates JHT, Roy GS, Charlebois C, Suki B, Smith BJ. Alveolar leak develops by a rich-get-richer process in ventilator-induced lung injury. PLoS One 2018;13:e0193934. http://doi: https://doi.org/10.1371/journal.pone.0193934.

20. Dushianthan A, Cusack R, Goss V, Postle AD, Grocott MP. Exogenous surfactant therapy for acute lung injury/acute respiratory distress syndromewhere do we go from here? Crit Care 2012;16:238-249. http://doi: https:// doi.org/10.1186/cc11512.

21. Rodríguez-Moya VS, Gallo-Borrero CM, Santos-Áreas D, Prince-Martínez IA, Díaz-Casañas E, López-Herce Cid J. Exogenous surfactant and alveolar recruitment in the treatment of the acute respiratory distress syndrome. Clin Respir J 2017;11:1032-1039. http://doi: https://doi.org/10.1111/cri.12462.

22. Boehne M, Sasse M, Karch A, Friederike Dziuba, Alexander Horke, Torsten Kaussen, et al. Systemic inflammatory response syndrome after pediatric congenital heart surgery: incidence, risk factors, and clinical outcome. J Card Surg 2017;32:116-125. http://doi: https://doi.org/10.1111/jocs.12879.

23. Matuschak GM, Lechner AJ. Acute lung injury and the acute respiratory distress syndrome: pathophysiology and treatment. Mo Med. 2010;107: 252-8. 
24. Willson DF, Thomas NJ, Markovitz BP, Bauman LA, DiCarlo JV, Pon S, et al. Effect of exogenous surfactant (calfactant) in pediatric acute lung injury: a randomized controlled trial. JAMA. 2005;293:470-476. http://doi: https://doi. org/10.1001/jama.293.4.470.

25. Alten JA, Borasino S, Pearce FB, Dabal RJ, Kirklin JK. Surfactant treatment for congenital heart disease patients with acute respiratory distress syndrome. Congenit Heart Dis 2010;5:624-628. http://doi: https://doi.org/10.1111/j. 1747-0803.2010.00412.x.

26. Qiu W, Zheng L, Gu H, Chen D, Chen Y. Comparison between adult and infant lung injury in a rabbit ischemia-reperfusion model. J Thorac Cardiovasc Surg 2008;136:352-359. http://doi: https://doi.org/10.1016/j.jtcvs. 2008.01.014

27. Filoche M, Tai CF, Grotberg JB. Three-dimensional model of surfactant replacement therapy. Proc Natl Acad Sci U S A 2015;112:9287-9292. http:// doi: https://doi.org/10.1073/pnas.1504025112.

\section{Publisher's Note}

Springer Nature remains neutral with regard to jurisdictional claims in published maps and institutional affiliations.

Ready to submit your research? Choose BMC and benefit from:

- fast, convenient online submission

- thorough peer review by experienced researchers in your field

- rapid publication on acceptance

- support for research data, including large and complex data types

- gold Open Access which fosters wider collaboration and increased citations

- maximum visibility for your research: over $100 \mathrm{M}$ website views per year

At BMC, research is always in progress.

Learn more biomedcentral.com/submissions 